\title{
STRATEGOI: A SPOC TO TEACH ANCIENT GREEK ${ }^{1}$
}

\author{
Raquel Fornieles \\ Department of Classics, Autonomous University of Madrid (Spain)
}

\begin{abstract}
We present the SPOC (Small Private Online Course) 'STRATEGOI'. The Wars between Greeks and Persians. This course, created on the UAMX platform for the subject Greek I (first semester of the second year of the Degrees in Sciences and Languages of Antiquity and Art History and Sciences and Languages of Antiquity) has been implemented for the first time in the current academic year (2018/2019) following the Flipped Classroom methodology. The final results of the experience are also shown.
\end{abstract}

Keywords: Ancient Greek, 'spoc', flipped classroom, greco-persian wars.

\section{Introduction}

Throughout the 2017/2018 academic year, a group of professors from the Departments of Classics and Ancient History of the Autonomous University of Madrid ${ }^{2}$ worked on the development of an SPOC (Small Private Online Course) on the UAMX platform. The SPOC, called STRATEGOI. The wars between Greeks and Persians (STRATEGOI hereinafter) was created to meet the needs of the students enrolled in the subject Greek I (first semester of the second year of the Degrees in Sciences and Languages of Antiquity and Art History and Sciences and Languages of Antiquity) $)^{3}$. Students access both Degrees having a very unequal level of knowledge of Ancient Greek (there are even those who have never studied Greek before). For this reason, from the first academic year (in the subject Fundamentals of the Greek Language $e^{4}$ ), students are divided into two groups: A (for those who learnt Ancient Greek in High School) and B (aimed at those students who do not know Greek or show significant knowledge gaps). This split disappears in the third academic year, hence it is essential that group B students reach, during their second academic year, a level as close as possible to those of group A.

For this purpose, the final exam of Greek I is common and identical for both groups. This means that both teachers and students must make a considerable effort for all students to acquire - at the end of the course - the necessary skills to successfully face the translation of the same texts and the completion of the same exercises (grammar and syntax).

Our main objective is, therefore, that STRATEGOI becomes a useful tool to ensure that group B students optimize their performance and consolidate their knowledge in a novel and motivational way. In addition to this, when our project began we thought that the SPOC could be useful also for students in group A, since they would have a very complete resource to reinforce their weak points and to review several contents. As it will be explained later in this paper, our purposes have been fulfilled.

\section{Design: the $S P O C$ on the platform $U A M X$}

According to the topic of the subject Greek I, the SPOC is about the Greco-Persian Wars, a series of armed conflicts between the Greek City-States and the Achaemenid Empire (5th century BC). Therefore, STRATEGOI, based on videos, interactive infographics and exercises, begins with an

\footnotetext{
${ }^{1}$ This work has been developed within the framework of two Teaching Innovation projects funded by the Teaching Innovation program of the Autonomous University of Madrid: Strategoi. The Wars between Greeks and Persians (FYL_001.17_INN) and Application of Flipped Classroom to Greek I: SPOC STRATEGOI (FyL_016.18_IMP).

${ }^{2}$ The six members of the work are Luz Conti, Raquel Fornieles (both coordinators), Claudia Alonso, Helena González, Alberto Pardal and Jesús Robles.

${ }^{3}$ The students of both Degrees attend this course together.

${ }^{4}$ In fact, STRATEGOI was conceived as the continuation of another SPOC aimed specifically at the students of the group B of this subject. This previous course, called Kybernetes. Course 0 of Classical Greek, was implemented throughout the 2016/2017 academic year with excellent results. On Kybernetes, see Fornieles (2017) and González (2018).
} 
introduction to those wars (background, chronology, Herodotus and his dialect). Afterwards, contents are organized in four modules, each one named as one of the main battles of the Greco-Persian Wars:

1. Marathon

2. Salamis

3. Thermopylae

4. Plataea

In turn, each module is divided into seven different sections: 'Presentation', 'Historical Context', 'The Strategoi', 'Texts', 'Morphology', 'Syntax' and 'Lexicon'.

A fifth block, called 'And Then ...' closes the course and serves to reflect on the consequences of the Greco-Persian Wars.

The design phase of the SPOC ended on June 30th, 2018. In this first stage 17 texts from the Histories of Herodotus (all of them are accompanied by an audio track) were adapted to the level of our students. 46 videos were recorded and 79 interactive infographics were created. Schemes and paradigms were also made, as well as a significant number of exercises through the UAMX platform itself. The following figures show some of those materials:

Figure 1. Adapted text from the Histories of Herodotus with audio track.

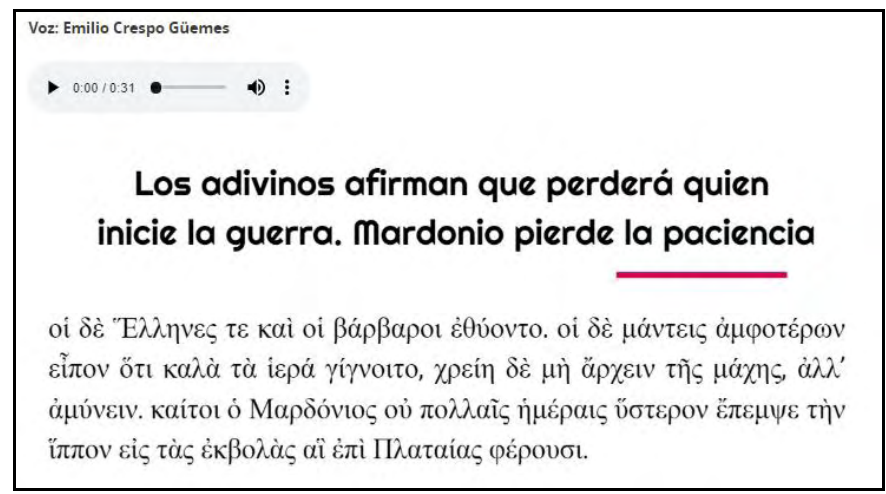

Figure 2. Video ${ }^{5}$ of the Historical Context of the Salamis module and Interactive Infographic of a lexical family.
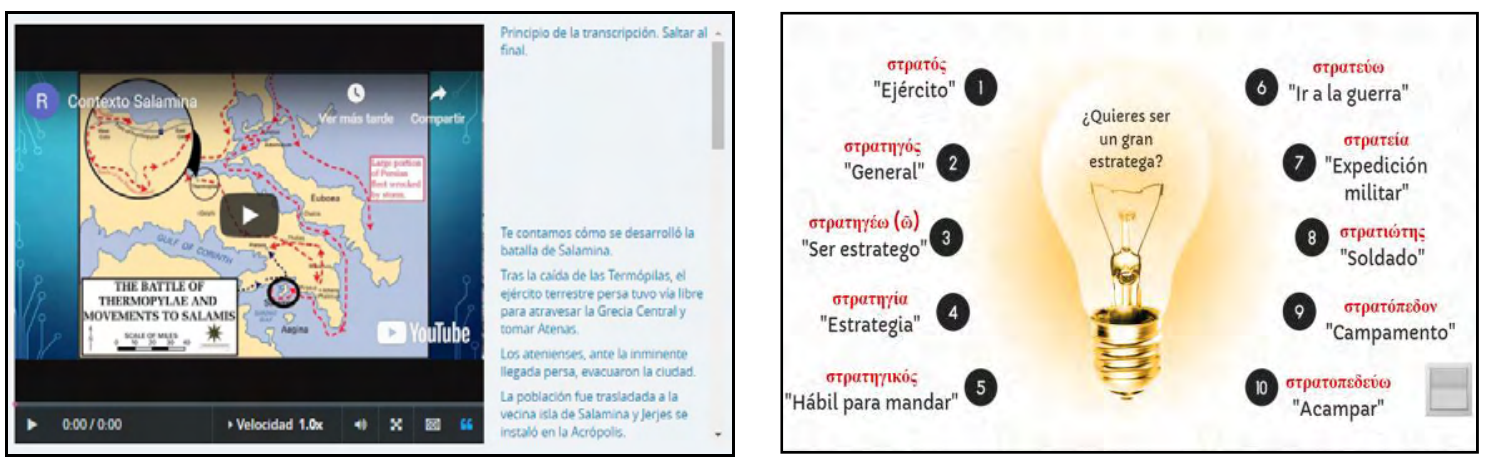

Figure 3. Example of a Multiple Choice exercise correctly solved with explanation ${ }^{6}$.

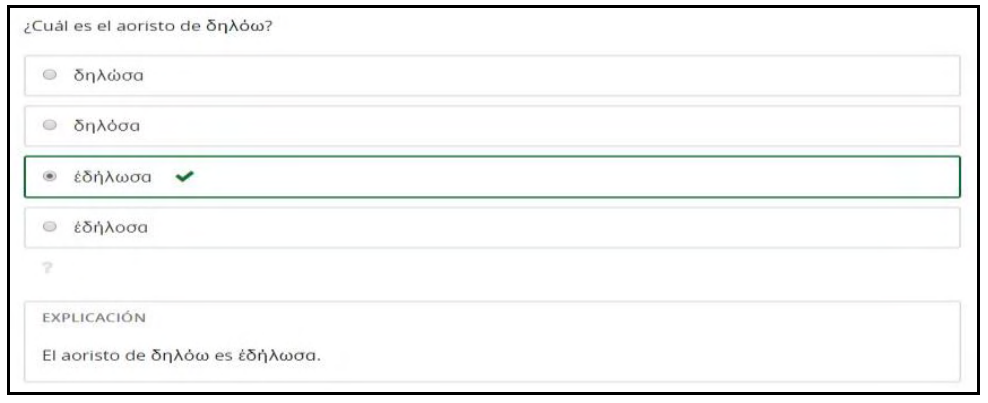

\footnotetext{
${ }^{5}$ Each video has its corresponding subtitles which can be downloaded by the students.

${ }^{6}$ The platform allows us to create different types of exercises: Multiple Choice, Blank Common Problem, Checkboxes, Dropdown, Numerical Input and Text Input. In all of them an option with Hints and Feedback can be activated.
} 


\section{Implementation and methodology: The Flipped Classroom}

The subject Greek $I$ has been taught in the first semester of the current academic year. This means that the SPOC has been put into practice for the first time between the months of September 2018 and January 2019.

To achieve our goals we have implemented the Flipped Classroom methodology, a Blended Learning modality which reverses the traditional learning environment by combining face-to-face teaching with the autonomous work carried out by the students outside the classroom. There is no unique and universal definition of Flipped Classroom ${ }^{7}$. The model was popularized by two teachers in the University of Colorado, Jonathan Bergmann and Aaron Sams. Concerned with students who often missed their lessons, and after accessing a software that allowed them to record PowerPoint presentations, began to record slides, complete lectures, etc. Once the recording tasks were finished, they posted the materials on YouTube. Students were expected then to view the videos and so the class was 'inverted': the so-called homework was done in the classroom and those teachers encouraged active and collaborative learning.

Taking this proposal as a starting point, we have 'flipped' the classroom of Greek I. According to a schedule previously provided by the teacher, students (group B) have followed - progressively and successfully - the course and the proposed objectives have been fulfilled. The completion and monitoring of the SPOC has been combined with the translation and commentary of texts in the classroom (different from those texts included in the SPOC). Mid-term exams (morphology, syntax and vocabulary) have been made to verify the progress of the students and to check the viability of the methodology.

\section{Results and conclusions}

At the end of the semester all the data offered by the platform were analyzed in detail and the general results obtained with the implementation of the SPOC. The total number of students enrolled in Greek I was 33: 22 in group A and 11 in group B. The course was included in the Teaching Guide of the subject. The follow-up of the course and the execution of the activities were mandatory for group B (up to $20 \%$ of the final grade) and optional for group A. The monitoring of the individual progress of each student was carried out through the platform itself, since it allows the teacher to obtain specific data through the tool called 'Student's progress page'.

The final results were highly satisfactory and one aspect caught our attention: although the follow-up of the SPOC was not mandatory for group A, more than 70 percent of the students in that group decided to follow and complet it at the same pace as their peers.

We also wanted to take into account the opinions of the students themselves in order to draw definitive conclusions. We designed a survey to be filled out (anonymously) on the last day of the course. Students were expected to give their opinion on several aspects on a scale of 1 to 4 (1 lowest, 4 highest). The following figure reflects the results, really rewarding:

Figure 4. Data of the survey conducted on the SPOC.

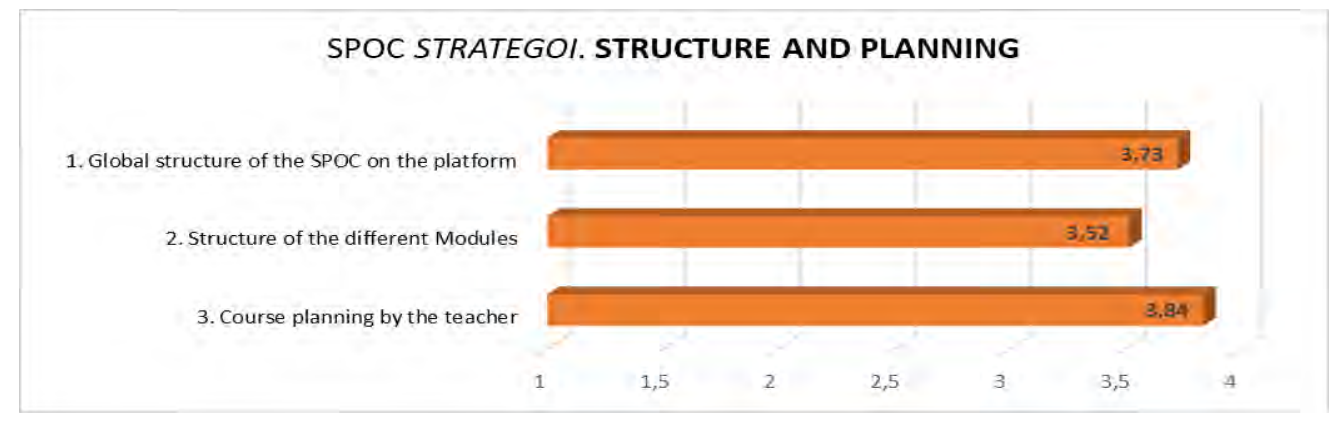

\footnotetext{
7 See Wolff \& Chan (2016: 9). They conclude: "However it appears that academics agree that a flipped classroom generally provides pre-recorded lectures (video or audio) followed by in-class activities". For additional information about Flipped Classroom see References list.
} 

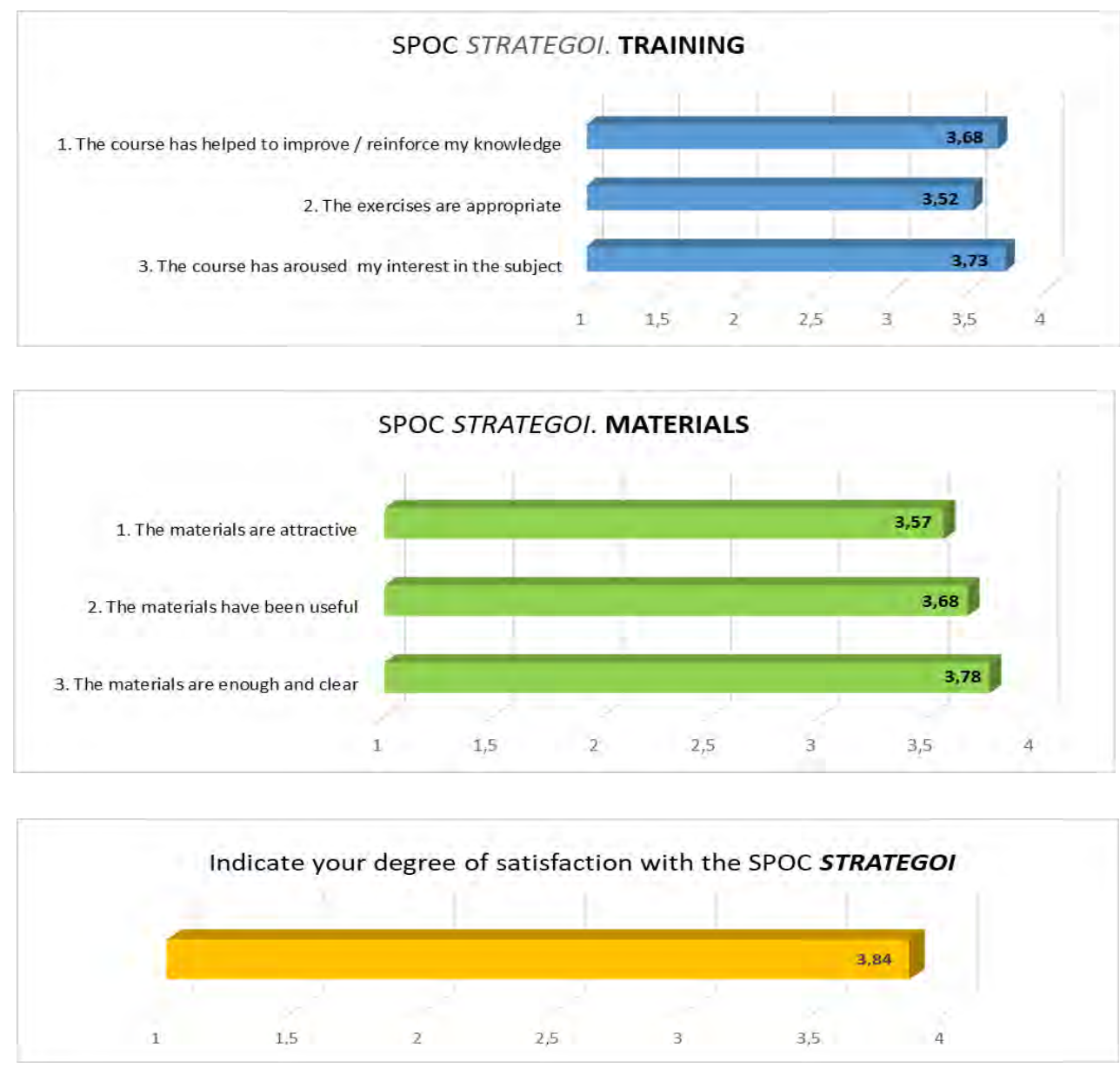
questions:

In addition to the questions shown in the graphics the survey included four open answer

1. What materials have you found most useful?

2. What aspect(s) would you highlight?

3. What aspect(s) would you change?

4. Do you have suggestions to improve the SPOC? Please, indicate them.

With regard to the materials, most of the students highlighted their preference for interactive infographics (they considered them really useful to study in a more enjoyable and effective way). The attractive presentation of the course on the platform and the implemented methodology ("highly motivating") are the most outstanding aspects in their opinion. Finally, their suggestions and comments will be considered in order to make an improvement plan for the next academic year.

\section{References}

Bergamnn, J. \& Sams, A. (2014). Flipped Learning; Gateway to Student Engagement. Eugene: Oregon International Society for Technology in Education.

Bergmann, J. \& Sams, A. (2014). Dale la vuelta a tu clase: lleva tu clase a cada estudiante, en cualquier momento y en cualquier lugar. Madrid: SM.

Calvillo, A. J. \& Martín, D. (Coords.). (2017). The 'Flipped Learning': guía 'gamificada' para novatos $y$ no tan novatos. La Rioja: UNIR.

Fornieles, R. (2017). Propuesta de aplicación de Blended Learning a la enseñanza de Griego I en Bachillerato. Tendencias Pedagógicas, 29, pp. 77-100. 
González, H. (2018). Kybernetes: un curso de introducción al Griego Clásico en la plataforma edX. In L. Jiménez Justicia (Ed.) Ianus: Innovación Docente y reelaboraciones del legado clásico (pp. 11-30). Coimbra: Imprensa da Universidade de Coimbra.

Prats, M.Á., Simón, J. \& Ojando, E. S. (Coords.). (2017). Diseño y aplicación de la Flipped Classroom. Experiencias en educación primaria y en la formación inicial de profesores. Barcelona: GRAO.

Reidsema, C., Kavanagh, L., Hadgraft, R. \& Smith, N. (Eds.). (2017). The Flipped Classroom: Practice and Practices in Higher Education. Singapore: Springer.

Stylianos, S., Sampson, D. G. \& Pelliccione, L. (2019). Investigating the Impact of Flipped Classroom on Students' Learning Experiences: A Self-Determination Theory Approach. Computers in Human Behavior, 2018, pp. 368-378.

Tourón, J., Santiago, R. \& Díez, A. (2014). The 'Flipped Classroom'. Cómo invertir la escuela en un espacio de aprendizaje. Madrid: Digital-Text.

Wolff, L-C. \& Chan, J. (2016). Flipped Classroom for Legal Education. Hong Kong: Springer. 